\title{
New Indoor Accelerated Weathering Condition for Approximating Molecular Weight Distribution of Outdoor-Exposed LDPE
}

\author{
Takashi Miwa $^{1 *}$, Yukitoshi Takeshita ${ }^{1}$, Yuichi Akage ${ }^{2}$, MasamitsuWatanabe $^{2}$, Masaaki Takaya ${ }^{2}$ and Takashi Sawada ${ }^{1}$ \\ 1. NTT Device Technology Labs, NTT Corporation 3-1, Morinosato-Wakamiya Atsugi-shi, Kanagawa 2430198, Japan \\ 2. Technical Assistance and Support Center, NTT East Corporation 1-2-5, kamata-honcho, Ota-ku, Tokyo 1440053, Japan
}

\begin{abstract}
LDPE (low-density polyethylene) photo degraded through various accelerated weathering tests has the molecular weight distribution curves unlike that through outdoor exposure. The authors therefore developed new weathering test condition based on the existing accelerated weathering test using a xenon arc lamp. Samples of LDPE were photo degraded using various accelerated weathering test conditions and outdoor exposure. The physical properties and chemical structures of the photo degraded samples were studied through a tensile test, infrared spectroscopy, and gel chromatography. The authors found that the molecular weight distribution curve of a sample photo degraded using a xenon lamp at a higher BPT (black panel temperature) $\left(73^{\circ} \mathrm{C}\right)$ was more similar to that of an outdoor-exposed sample than that of a sample photo degraded at the standard BPT $\left(63{ }^{\circ} \mathrm{C}\right)$. It is considered that higher temperature accelerates radical recombination, consequently recreating molecular enlargement similar to the outdoor-exposed sample. Multiple regression analysis using newly introduced Mp (peak-top molecular weight) and Mw (weight-average molecular weight) as explanatory variables was conducted, which successfully enabled the authors to provide a simple explanation for the decrease in polymer tensile strength.
\end{abstract}

Key words: LDPE, photo degradation, molecular weight distribution, accelerated weathering test, outdoor exposure, molecular enlargement.

\section{Introduction}

An accelerated weathering test using a xenon arc lamp is generally used to evaluate the weather ability of high polymer materials for outdoor use. The standard test condition of this test simulates the spectral irradiance of sunlight at the peak of mid-summer. Since the acceleration ratio of photo degradation during the test is not high, a long-term reliability evaluation of polymer materials takes thousands of hours; therefore, shortening the testing time is necessary. In addition, polymers photo degraded using various accelerated weathering instruments present molecular weight distribution curves unlike those photo degraded by outdoor exposure. Therefore, a new accelerated weathering

*Corresponding author: Takashi Miwa, master, research fields: polymer-based materials and corrosion technology. test condition is required to shorten the testing time and reconstruct the photo degradation behavior of outdoor-exposed polymer materials.

The thermo-oxidative degradation mechanism of polyolefin has been extensively investigated [1], the change in molecular weight distribution due to thermo-oxidative degradation has been reported [2]. Due to thermo-oxidation, various deterioration products (ketone, aldehyde, acid, ester, alcohol, ether, etc.) have been formed. In addition, the chain-scission and radical recombination occur in parallel, causing both molecular diminishment and molecular enlargement [2].

The photo degradation mechanism of polyolefin in the atmosphere is a photo-oxidation process which functions essentially the same as thermo-oxidation. The largest difference between thermo-oxidation and photo-oxidation is that Norrish reactions (types 1 and 2) 
occur in photo-oxidation not in thermo-oxidation [3, 4]. The photo degradation mechanism of polyolefin degraded due to outdoor exposure or accelerated weathering testing has been investigated in detail, and the photochemical reaction mechanism [5-14], IR (infrared) spectroscopy spectrum behavior [5, 8-15], and molecular weight and molecular weight distribution behavior [5, 9-11, 15] of photo degraded polyolefin have been reported.

The effect of temperature at photo degradation on molecular weight and molecular weight distribution has been reported [9]. David suggested that chain propagation is favored at higher temperature, which leads to a higher concentration of radicals; hence, to a higher probability of cross-linking. However, the test condition for approximating molecular weight distribution of outdoor-exposed sample has not been investigated.

In the authors previous study [16], the authors found that the molecular weight distribution of LDPE (low-density polyethylene) photo degraded using a FUV (fluorescent UV lamp) at a higher BPT (black panel temperature) $\left(80{ }^{\circ} \mathrm{C}\right)$ was more similar to that of an outdoor-degraded sample than those of other samples artificially photo degraded using a xenon arc lamp at standard BPT $\left(63{ }^{\circ} \mathrm{C}\right)$ or using a FUV at standard BPT $\left(60{ }^{\circ} \mathrm{C}\right)$. It was considered that the accelerated weathering tests at higher sample temperature could accelerate cross-linking by radical recombination more than chain-scission for molecules of high molecular weight, consequently recreating molecular-enlargement similar to that of the outdoor-exposed sample.

Thus, the objective of this study was to examine whether the accelerated weathering test using three kinds of instruments other than FUV at higher BPT than standard BPT can accelerate radical recombination than chain-scission for molecules of high molecular weight under LDPE photo degradation, resulting in the recreation of molecular-enlargement similar to outdoor degraded sample. The physical properties and chemical structures of the photo degraded samples were studied using a tensile test, gel chromatography, and infrared spectroscopy. A trial of multiple regression analysis between tensile strength and newly introduced Mp (peak-top molecular weights) and $\mathrm{Mw}$ (average-weight molecular weights) was also conducted.

\section{Experiments}

\subsection{Sample Preparation}

Commercial additive-free LDPE synthesized by Dow Chemical Japan, LDPE DFDJ-0588NT was used and $1.0 \mathrm{~mm}$-thick LDPE sheets were formed by hot press at $150 \pm 5{ }^{\circ} \mathrm{C}, 10 \mathrm{MPa}$. The $\mathrm{Mn}$ (number-average molecular weights) and and $\mathrm{Mw}$ respectively were 19,100 and 338,000 determined by GPC (gel permeation chromatography). The sheets were used for an outdoor weathering test. Further test pieces of ISO 37 type 1A, which were punched out from the LDPE sheets, were used for the accelerated weathering tests.

\subsection{Accelerated Weathering Test}

The LDPE test pieces were placed in an irradiation chamber. The following three weathering instruments were used in this study. The Atlas XWOM (Xenon Weather-Ometer Ci4000) has a xenon arc lamp with spectral irradiance close to sunlight. The SXWM (Suga Super Xenon Weather Meter SX75) has the same light spectra xenon arc lamp at $180 \mathrm{~W} / \mathrm{m}^{2}$ of UV irradiance, which is three times higher than that of XWOM UV irradiance $\left(60 \mathrm{~W} / \mathrm{m}^{2}\right)$, and can lower UV irradiance and be also used instead of XWOM. The MWM (Suga Metaling Vertical Weather Meter MV3000) has a metal halide lamp that irradiates at high UV irradiance $\left(530 \mathrm{~W} / \mathrm{m}^{2}\right)$.

Table 1 lists six test conditions under which these instruments were used. XWOM-ST (XWOM standard) condition was used according to ISO11341 Cycle No. 9 and repeated the cycle consisting of $102 \mathrm{~min}$ UV-irradiation and 18 min UV-irradiation with spray cycles at $60 \mathrm{~W} / \mathrm{m}^{2}$ of $\mathrm{UV}$ 
Table 1 Accelerated weathering conditions.

\begin{tabular}{|c|c|c|c|c|c|c|}
\hline \multirow{2}{*}{$\begin{array}{l}\text { Test name } \\
\text { (Instrument) }\end{array}$} & \multicolumn{4}{|c|}{ UV exposure } & \multicolumn{2}{|r|}{ UV exposure + spray } \\
\hline & $\begin{array}{l}\text { Time } \\
(\mathrm{min})\end{array}$ & Irradiance $\left(\mathrm{W} / \mathrm{m}^{2}\right.$ at $\left.300-400 \mathrm{~nm}\right)$ & $\begin{array}{l}\mathrm{BPT}^{\mathrm{I}} \\
\left({ }^{\circ} \mathrm{C}\right)\end{array}$ & $\begin{array}{l}\mathrm{AT}^{2} \\
\left({ }^{\circ} \mathrm{C}\right)\end{array}$ & $\begin{array}{l}\text { Time } \\
(\mathrm{min})\end{array}$ & Irradiance $\left(\mathrm{W} / \mathrm{m}^{2}\right.$ at $\left.300-400 \mathrm{~nm}\right)$ \\
\hline XWOM-ST (Ci4000) & 102 & 60 & 63 & 38 & 18 & 60 \\
\hline XWOM-HT (SX75) & 102 & 60 & 73 & 48 & 18 & 60 \\
\hline SXWM-ST (SX75) & 102 & 180 & 63 & 38 & 18 & 180 \\
\hline SXWM-HT (SX75) & 102 & 180 & 83 & 48 & 18 & 180 \\
\hline MWM-ST (MV3000) & 102 & 530 & 63 & 38 & 18 & 530 \\
\hline MWM-HT (MV3000) & 102 & 530 & 83 & 38 & 18 & 530 \\
\hline
\end{tabular}

* Bold shows point at which BPT and/or AT (air temperature) changes between -HT (SXWM high-temperature) and -ST.

irradiance, BPT $63{ }^{\circ} \mathrm{C}$, chamber AT $38{ }^{\circ} \mathrm{C}$, and $50 \%$ RH (relative humidity). The SXWM-ST and MWM-ST were the same as those of XWOM, except the UV irradiance and UV irradiance of SXWM-ST and MWM-ST were $180 \mathrm{~W} / \mathrm{m}^{2}$ and $530 \mathrm{~W} / \mathrm{m}^{2}$, respectively. The XWOM high-temperature condition (XWOM-HT) provided higher BPT $\left(73{ }^{\circ} \mathrm{C}\right)$ and $\mathrm{AT}\left(48{ }^{\circ} \mathrm{C}\right)$ than XWOM-ST. In XWOM-HT, Suga SX75 lowered UV irradiance the same as XWOM. The SXWM-HT condition provided higher BPT $\left(83^{\circ} \mathrm{C}\right)$ and AT $\left(48{ }^{\circ} \mathrm{C}\right)$ than SXWM-ST. The MWM high-temperature condition (MWM-HT) provided higher BPT $\left(83{ }^{\circ} \mathrm{C}\right)$ than MWM-ST. From these accelerated weathering tests, samples for analysis were extracted at different times.

\subsection{Outdoor Weathering Test}

The LDPE sheets were mounted on exposure decks with $45^{\circ}$ southward inclination from May 2011 to May 2012 at Choshi outdoor weathering test site of the Japan weathering test center (Choshi city, Chiba Pref. Japan). From the outdoor weathering tests, the LDPE sheets for analysis were extracted at different times, and ISO 37 type 1A test pieces were punched out from the exposed LDPE sheets.

\subsection{Mechanical Properties}

The ultimate tensile strength and elongation at break of test pieces were measured through tensile tests using Shimadzu Autograph AG-X Universal/Tensile Testers with a crosshead separation speed of $200 \mathrm{~mm} / \mathrm{min}$ at $23 \pm 2^{\circ} \mathrm{C}, 50 \% \mathrm{RH}$. Five to twelve test pieces were tested for all weathering conditions and test times, the average value and the standard deviation were calculated.

\subsection{FT-IR Spectroscopy}

The infrared measurements of the test pieces were carried out using PerkinElmer FT-IR (Fourier transform infrared) spectoscopy Frontier Gold with a single reflection diamond ATR (attenuated total reflection) accessory. ATR technique was used to enhance surface sensitivity toward photo-oxidation. The test pieces, which photo degraded at approximately the same degree (around 15-17 $\mathrm{MPa}$ tensile strength and around 500\%-600\% elongation), were selected.

\subsection{Molecular Weight Distributions}

For GPC analysis, approximately $0.1 \mathrm{~mm}$-thick LDPE samples were scraped off from the irradiated side and reverse side of the test pieces. The test pieces, which photo degraded at approximately the same degree (around 15-17 MPa tensile strength and around $500 \%-600 \%$ elongation), were selected. The molecular weight characteristics of the selected samples were obtained by GPC (Waters Alliance GPC 2000) with a refractive index detector and four columns (Two columns were Tosoh TSK gel MH6-HT and other two columns were Tosoh TSK gel GMH6-HTL). The solvent was o-dichlorobenzene at $140{ }^{\circ} \mathrm{C}$ and 1.0 $\mathrm{mL} / \mathrm{min}$ flow rate. The molecular weight averages $(\mathrm{Mw}$ 
and $\mathrm{Mn}$ ) were calculated using a universal calibration curve constructed in accordance with the polystyrene standard. Insoluble material was not observed at the non-exposed sample but was observed at the photo degraded samples. However, GPC analysis was carried out only on the soluble part in this study.

\section{Results and Discussions}

\subsection{Mechanical Properties Changes}

Figs. 1 and 2 show the tensile strength and elongation of all samples. To compare the acceleration ratio of degradation through accelerated weathering tests, the regression analysis was conducted. Because the relative standard deviations of tensile strength were lower than those of elongation and the tensile strength decreased linearly, the regression analysis was conducted using tensile strength as the target variable and the weathering test time as the explanatory variable. The relative acceleration ratios were calculated from the regression coefficients. The results are presented in Table 2.

The calculated relative acceleration ratios taking the level of XWOM-ST as a base of 1.00 were 1.64 (XWOM-HT), 1.28 (SXWM-ST), 3.07 (SXWM-HT), 3.52 (MWM-ST), and 5.58 (MWM-HT). For comparison, when elongated, the relation of acceleration ratios among six test conditions is as follows.

$$
\text { MWM-HT }>\text { MWM-ST } \approx(\geq) \text { SXWM-HT > }
$$

\section{XWOM-HT > SXWM-ST > XWOM-ST}

Increasing the BPT shortened the test time for the same degree degradation of physical properties. This result is consistent with those using tensile strength described above. Fig. 3 shows the relationship between tensile strength (retention percent) and elongation (retention percent) for all samples. The data obtained in the authors previous study [16] was added to Fig. 3.

At a range of $50 \%-100 \%$ elongation retention, the relationship between tensile strength and elongation was directly proportional. However, at a range of $0-50 \%$ elongation retention, tensile strength did not decrease and remained constant. As a result of the regression analysis between tensile strength and elongation at a range of 50\%-100\% elongation retention, Eq. (1) was obtained.

$$
y=0.818 x+17.7, R^{2}=0.70
$$

There was no different point far from the regression line, and the relationship between tensile strength. It is noted that elongation was expressed in only one line, regardless of the type of accelerated weathering instrument or test condition.

\subsection{Changes in IR Spectrum}

Figs. 4-6 show the charts of IR analysis. The IR spectra were obtained from samples that photo degraded at approximately the same tensile strength degree (around 15-17 MPa).

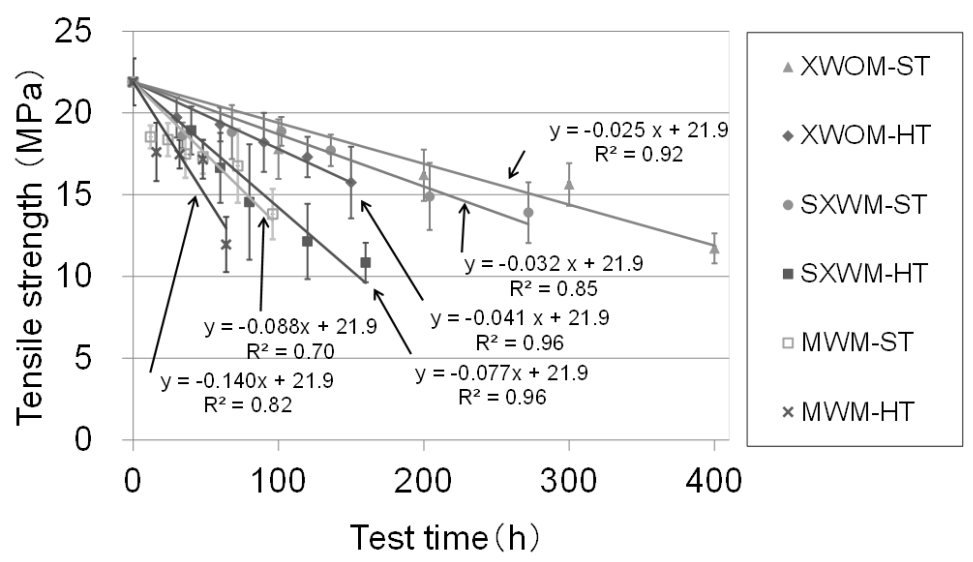

Fig. 1 Tensile strength after accelerated weathering tests (XWOM-ST is from [16]). 


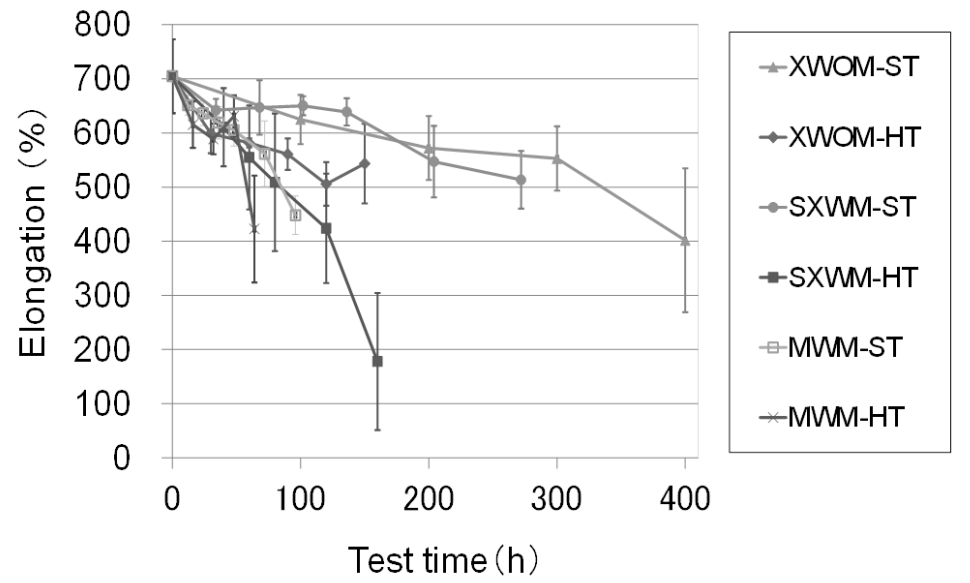

Fig. 2 Elongation after accelerated weathering tests (XWOM-ST is from [16]).

Table 2 Result of regression analysis.

\begin{tabular}{llll}
\hline Test condition & Regression coefficient & Acceleration ratio $(\mathrm{XWOM}=1)$ & Coefficient of determination $\left(\mathrm{R}^{2}\right)$ \\
\hline XWOM-ST* & -0.0250 & 1 & 0.915 \\
XWOM-HT & -0.0410 & 1.64 & 0.955 \\
SXWM-ST & -0.0320 & 1.28 & 0.853 \\
SXWM-HT & -0.0768 & 3.07 & 0.957 \\
MWM-ST & -0.0881 & 3.52 & 0.697 \\
MWM-HT & -0.1399 & 5.58 & 0.818 \\
\hline
\end{tabular}

* XWOM-ST is from [16].

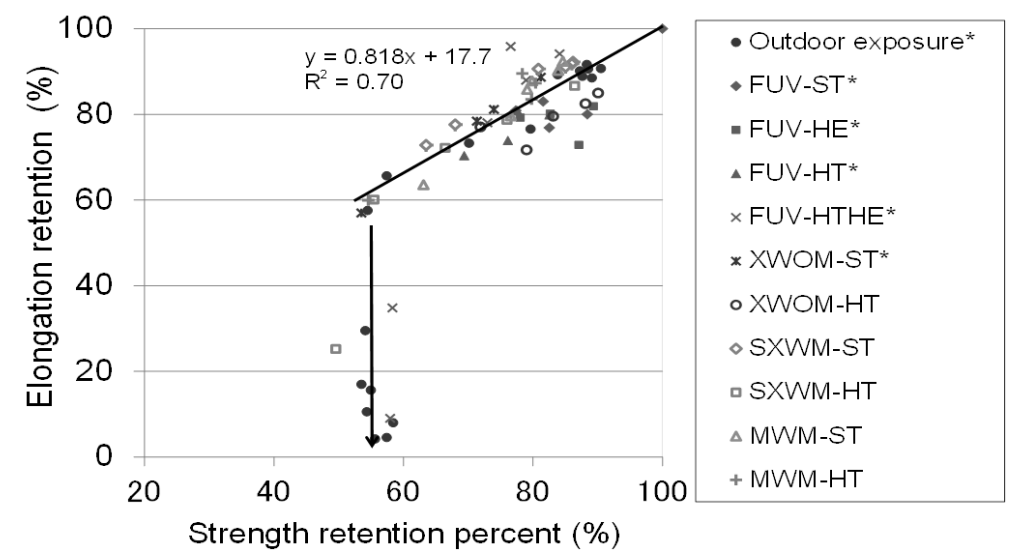

Fig. 3 Relationship between tensile strength and elongation after accelerated weathering tests (plots of [*] are from [16]).

Research on the degradation mechanism of high-polymer material has been developed, and the oxidative degradation mechanism, which is based on "auto-oxidation (auto-acceleration)", was currently established [1, 2]. Photo degradation, which is "auto-oxidation" involving photochemical reaction, is started by radical production caused by the effect of light and heat. It has been reported that radical recombination (molecular-enlargement), chain-scission, formation of carbonyl compounds (ketone, acid, aldehyde, ester etc.), hydroxyl group and peroxy group, vinyl group, etc. occur during photo degradation of polyolefin [5-15].

The photo degraded PE (polyethylene) is known to exhibit a carbonyl absorption peak at $1,715 \mathrm{~cm}^{-1}$. This is the absorption peak of $\mathrm{C}=\mathrm{O}$ bond stretching (ketone, carbonyl acid. etc.) $[5,9,10,12-15]$. In Figs. 4-6, the outdoor-exposed sample exhibited stronger carbonyl absorption at $1,715 \mathrm{~cm}^{-1}$ than the non-exposed sample. 


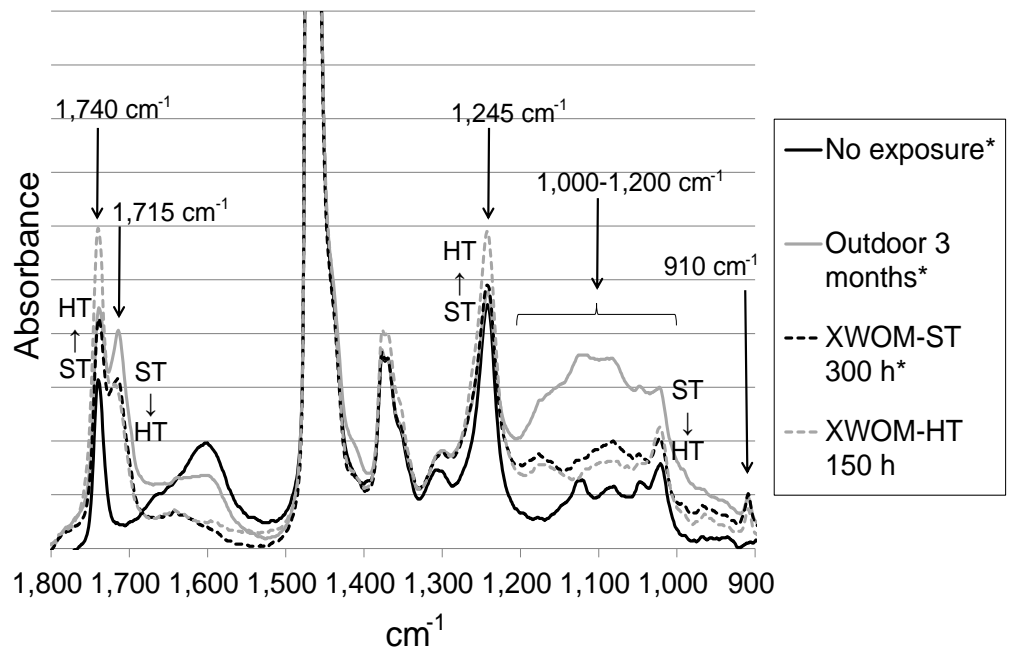

Fig. 4 IR spectra of photo degraded samples using XWOM (spectra of [*] are from [16]).

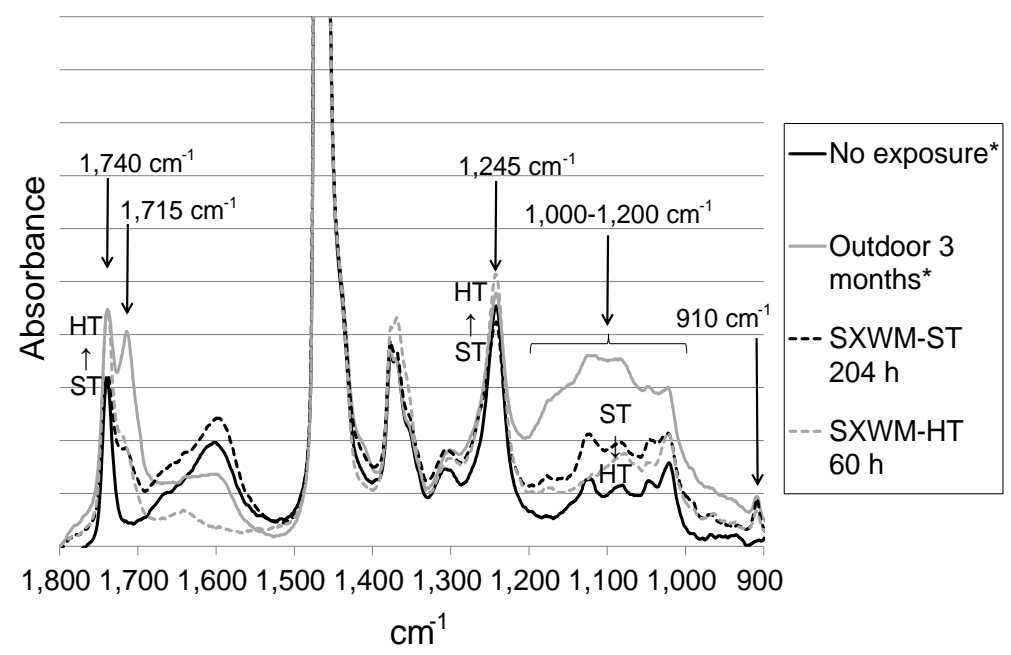

Fig. 5 IR spectra of photo degraded samples using SXWM (spectra of [*] are from [16]).

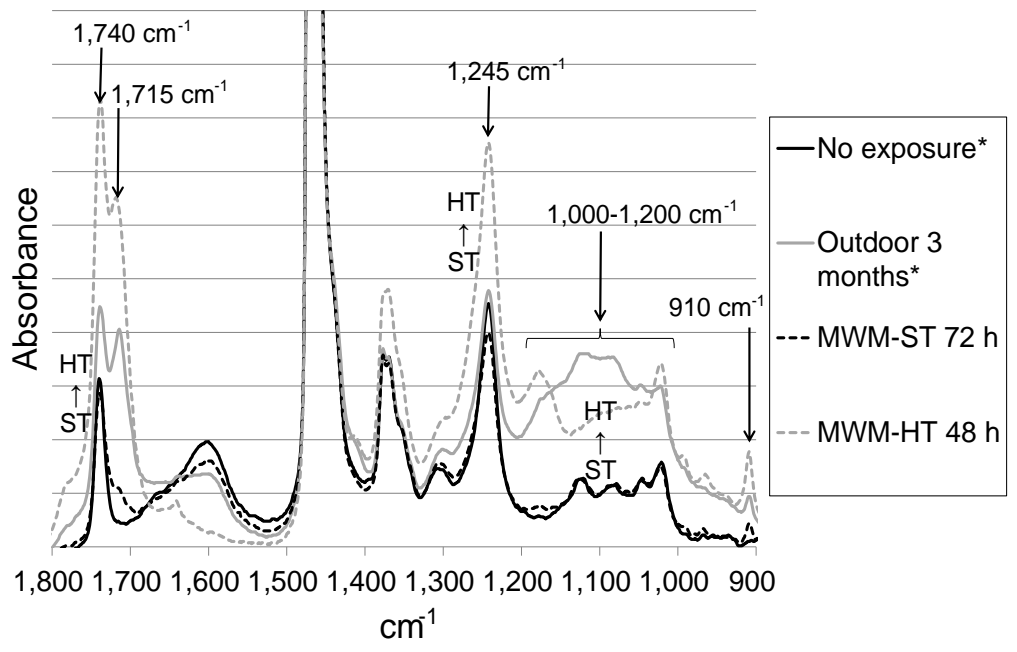

Fig. 6 IR spectra of photo degraded samples using MWM (spectra of [*] are from [16]). 
However, the samples photo degraded using XWOM (Fig. 4) and SXWM (Fig. 5) did not exhibit a noticeable absorption peak at $1,715 \mathrm{~cm}^{-1}$ as with the outdoor-exposed samples. In the authors previous study using FUV [16], the carbonyl absorptions of photo degraded LDPE samples at low temperature and/or low UV irradiation tended to be larger than those at high temperature and/or high UV irradiation. In this current study, the IR spectra of photo degraded LDPE were compared among XWOM-ST/-HT and SXWM-ST/-HT. In Fig. 4, the sample after XWOM-ST exhibited larger carbonyl absorption than that after XWOM-HT similarly. In Fig. 5, the sample after SXWM-ST exhibited larger carbonyl absorption than that after SXWM-HT. When the samples photo degraded at approximately the same degree (about 15-17 MPa tensile strength and 500\%-600\% elongation) were compared, the carbonyl absorptions of the samples photo degraded at lower temperature and/or lower UV irradiation tended to be larger than those at higher temperature and/or higher UV irradiation. The outdoor-exposed sample exhibited larger carbonyl absorption than that after XWOM-ST. The authors consider that this is because the outdoor conditions, except for solar culmination time of mid-summer, resulted in lower temperature and lower UV irradiation than from XWOM-ST $\left(60 \mathrm{~W} / \mathrm{m}^{2}\right.$ at 300-400 nm, BPT $63{ }^{\circ} \mathrm{C}$, AT $38^{\circ} \mathrm{C}$ ).

Carbonyl compounds are also formed by thermo-oxidation. The known difference between thermo-oxidation and photo-oxidation is whether Norrish reactions (types 1 and 2) occur in the oxidation mechanism [3, 4]. The vinyl group is formed due to the reaction of Norrish reaction type 2 [4]; therefore, vinylene and vinyl unsaturation, which were not found in thermo-oxidation, are formed due to photo-oxidation. In this current study, all photo degraded samples showed absorption peaks at $910 \mathrm{~cm}^{-1}$, which was attributed to vinyl saturation (Figs. 4-6). In terms of other vinyl absorption $\left(990 \mathrm{~cm}^{-1}\right)$ and vinylene absorption $\left(965 \mathrm{~cm}^{-1}\right)$ peaks, which were reported in previous studies [8, 9, 12-15], in this current study, minute peaks at $965 \mathrm{~cm}^{-1}$ and $990 \mathrm{~cm}^{-1}$ were identified in some samples, but a clear peak was not identified in other samples.

The absorption peak at $1,740 \mathrm{~cm}^{-1}$ is attributed to ester [5, 9, 12-14], which is a carbonyl compound, and the absorption at $1,740 \mathrm{~cm}^{-1}$ is due to $\mathrm{C}=\mathrm{O}$ bond stretching. There was ester absorption in the non-exposed sample, and the ester absorption increased with photo degradation. It is known that mechanical stress on PE causes degradation. In the presence of oxygen, a peroxy radical is formed then changes to ester [17]. In the authors study, the ester absorption in the non-exposed samples might have occurred due to mechanical stress of $10 \mathrm{MPa}$ at hot press for LDPE sheet forming described in the experimental section. In Figs. 4-6, when the IR spectra of photo degraded LDPE were compared among XWOM-ST/-HT, SXWM-ST/-HT, and MWM-ST/-HT, respectively, the samples photo degraded at higher temperature exhibited larger absorption at $1,740 \mathrm{~cm}^{-1}$ than those photo degraded at lower temperature.

The peaks at $1,000-1,200 \mathrm{~cm}^{-1}$ and $1,245 \mathrm{~cm}^{-1}$ were considered due to $\mathrm{C}-\mathrm{O}$ bond stretching of ester, ether, alcohol, etc. $[9,12,14]$. The relationship between the peak sizes of 1,740 and $1,245 \mathrm{~cm}^{-1}$ reveals a positive correlation; therefore, the peak at $1,245 \mathrm{~cm}^{-1}$ is considered due to $\mathrm{C}-\mathrm{O}$ bond stretching of ester. The size of the peak at $1,000-1,200 \mathrm{~cm}^{-1}$ has little correlation with the size of the $1,740 \mathrm{~cm}^{-1}$ peak; therefore, the peak at $1,000-1,200 \mathrm{~cm}^{-1}$ is considered due to $\mathrm{C}-\mathrm{O}$ bond stretching derived from not ester but ether and/or alcohol. The outdoor-exposed sample had a larger peak at $1,000-1,200 \mathrm{~cm}^{-1}$ than those photo degraded through accelerated weathering tests. Moreover, when the samples photo degraded at approximately the same degree (about 15-17 $\mathrm{MPa}$ tensile strength and 500\%-600\% elongation) were compared, those photo degraded at lower temperature exhibited larger absorption at 1,000-1,200 $\mathrm{cm}^{-1}$ than 
those photo degraded at higher temperature. These results suggest the same tendency of the forementioned carbonyl absorption $\left(1,715 \mathrm{~cm}^{-1}\right)$. There is no noticeable difference in the $1,000-1,200 \mathrm{~cm}^{-1}$ IR spectra between the samples after XWOM-ST and that after SXWM-ST; therefore, the difference in UV irradiation between XWOM $\left(60 \mathrm{~W} / \mathrm{m}^{2}\right)$ and SXWM $\left(180 \mathrm{~W} / \mathrm{m}^{2}\right)$ have an insignificant effect on the $1,000-1,200 \mathrm{~cm}^{-1}$ IR spectrum.

The outdoor conditions, except for the solar culmination time of mid-summer, show lower temperature and lower UV irradiation than those from XWOM-ST $\left(60 \mathrm{~W} / \mathrm{m}^{2}\right.$ at $300-400 \mathrm{~nm}$, BPT $63{ }^{\circ} \mathrm{C}$, at $38{ }^{\circ} \mathrm{C}$ ), and the outdoor-exposed samples exhibited larger carbonyl absorption than that after XWOM-ST. According to the above results, when samples photo degraded at approximately the same tensile strength, photo degradation at lower temperature and longer time is believed to cause a higher incidence of ether and/or alcohol.

In the authors previous study [16], a sample after FUV-HTHE (BPT $80{ }^{\circ} \mathrm{C}, 1.28 \mathrm{~W} / \mathrm{m}^{2}$ at $310 \mathrm{~nm}$ ) (test time $32 \mathrm{~h}$, tensile strength $16.0 \mathrm{MPa}$ ) exhibited no carbonyl absorption $\left(1,715 \mathrm{~cm}^{-1}\right)$, but after a longer FUV-HTHE (test time $72 \mathrm{~h}$, tensile strength $12.9 \mathrm{MPa}$ ), carbonyl absorption clearly formed. Costa et al. [12] reported that $1,715 \mathrm{~cm}^{-1}$ absorption peak began to form after the $1,740 \mathrm{~cm}^{-1}$ peak began to form. They also suggested the following two reaction pathways of PE photo degradation. Path 1 involves the decomposition of primary alkyl peroxides to esters through a concerted mechanism that does not involve free radical formation. Path 2 involves that radicals of uncertain origin are the initiating species of the second reaction path, as seen in the pure thermo-oxidative mechanism. The $1,715 \mathrm{~cm}^{-1}$ absorption peak began to form after the $1,740 \mathrm{~cm}^{-1}$ peak began to form; therefore, it is considered that esters are formed by path 1 at the initial stage of photo degradation and attributable fraction of esters formation by path 2 increase gradually at the next stage. In this and previous studies $[12,16]$, the following two findings were obtained.

1: Carbonyl absorption $\left(1,715 \mathrm{~cm}^{-1}\right)$ began to form after the ester absorption $\left(1,740 \mathrm{~cm}^{-1}\right)$ began to form;

2: In the samples photo degraded at approximately the same tensile strength (about 15-17 MPa), photo degradation at lower temperature, lower UV irradiation, and longer time resulted in a higher incidence of carbonyl compounds $\left(1,715 \mathrm{~cm}^{-1}\right.$ absorption).

The mechanism of these phenomena in this study is considered to be as follows. At high temperature (and/or high UV irradiation), particular reactions for ester formation in "auto-oxidation" are accelerated much more than reactions for carbonyl (acid, ketone) formation. After long photo degradation, carbonyls (acid, ketone) accumulate; therefore, $1,715 \mathrm{~cm}^{-1}$ absorption begins to form after the $1,740 \mathrm{~cm}^{-1}$ peak begins to form.

However, in Fig. 6, the sample after MWM-HT exhibited larger carbonyl $\left(1,715 \mathrm{~cm}^{-1}\right)$ and ether and/or alcohol (1,000-1,200 $\left.\mathrm{cm}^{-1}\right)$ absorption than that after MWM-ST. These results are in conflict with those from other accelerated weathering instruments. As noted below, the degradation behavior of molecular weight using MWM was also reverse that of molecular weight using other accelerated weathering instruments. The metal halide lamp of MWM has a different spectral radiance characteristic from the solar light and xenon arc lamp, and the UV irradiation of MWM $\left(530 \mathrm{~W} / \mathrm{m}^{2}\right)$ has several times more energy as those of outdoor exposure (about $0-60 \mathrm{~W} / \mathrm{m}^{2}$ ), XWOM $\left(60 \mathrm{~W} / \mathrm{m}^{2}\right)$, or SXWM $\left(180 \mathrm{~W} / \mathrm{m}^{2}\right)$. Photo degradation using MWM has not been reported and there is not much data on photo degradation using MWM. Further experiments using MWM is necessary.

\subsection{Molecular Weight}

\subsubsection{Molecular Weight and Distribution}

Figs. 7-9 show the molecular weight distribution of 
the irradiated side of the test pieces photo degraded as approximately the same tensile strength (about 15-17 $\mathrm{MPa})$. Table 3 shows average $\mathrm{Mn}, \mathrm{Mp}, \mathrm{Mw}$ between the irradiated and reverse sides of the test pieces. These data were obtained in current and the authors previous studies [16].
The molecular weight distributions of samples photo degraded using XWOM were compared among non-exposed and outdoor-exposed samples. In Fig. 7, the molecular weight distributions of the outdoor-exposed sample exhibited a peak top at a lower molecular weight than that of the non-exposed

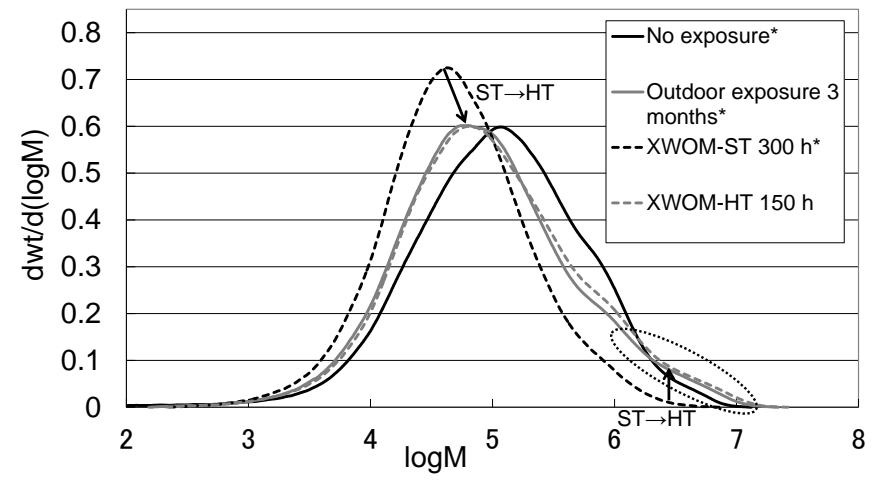

Fig. 7 Molecular weight distributions of samples photo degraded using XWOM (curves of [*] are from [16]).

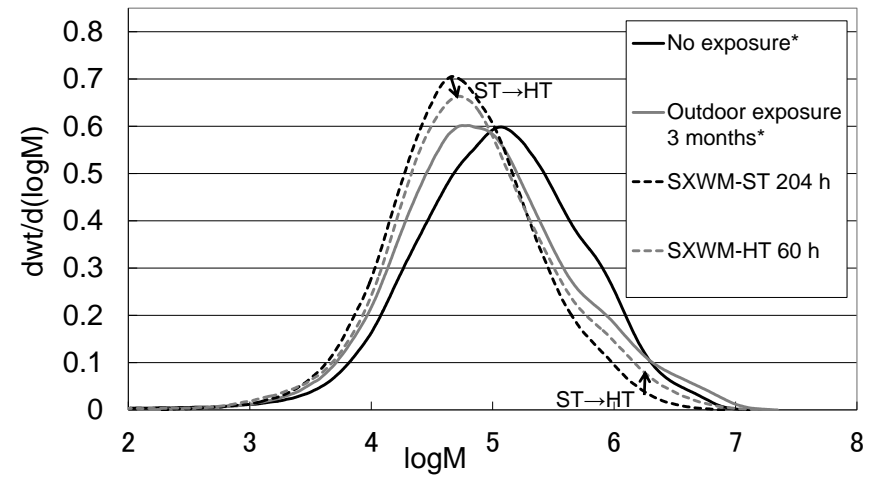

Fig. 8 Molecular weight distributions of samples photo degraded using SXWM (curves of [*] are from [16]).

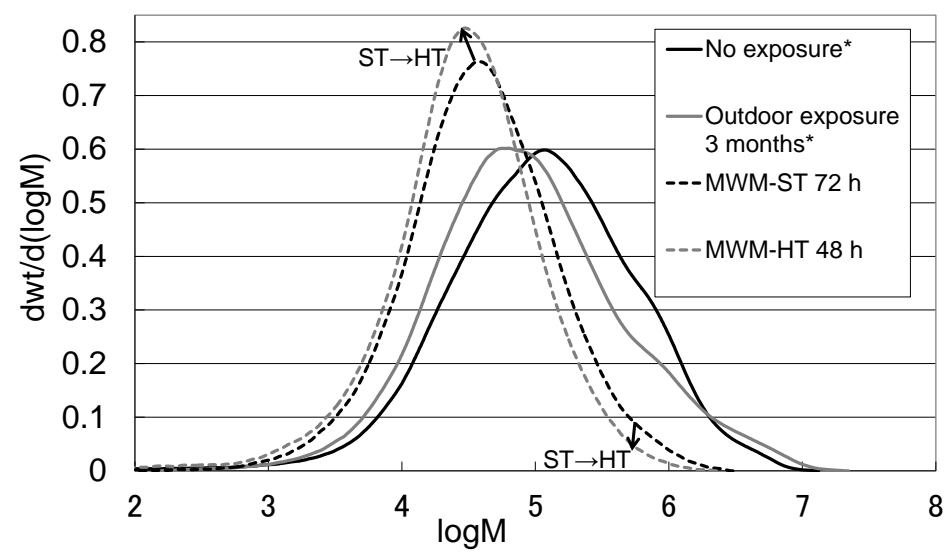

Fig. 9 Molecular weight distributions of samples photo degraded using MWM (curves of [*] are from [16]). 
Table 3 Molecular weight and physical properties.

\begin{tabular}{|c|c|c|c|c|c|c|c|c|c|}
\hline Weathering test & $\mathrm{Mn}^{*}$ & $\begin{array}{l}\mathrm{Mn} \\
\text { (retention } \\
\text { percent) }\end{array}$ & $\mathrm{Mp}^{*}$ & $\begin{array}{l}\mathrm{Mp} \\
\text { (retention } \\
\text { percent) }\end{array}$ & $\mathrm{Mw}^{*}$ & $\begin{array}{l}\text { Mw } \\
\text { (retention } \\
\text { percent) }\end{array}$ & $\mathrm{Mw} / \mathrm{Mn}$ & $\begin{array}{l}\text { Tensile } \\
\text { strength } \\
\left(\mathrm{N} / \mathrm{mm}^{2}\right)\end{array}$ & $\begin{array}{l}\text { Elongation } \\
(\%)\end{array}$ \\
\hline No exposure ${ }^{* *}$ & 19,100 & $100.0 \%$ & 141,000 & $100.0 \%$ & 338,000 & $100.0 \%$ & 17.7 & 21.9 & 705 \\
\hline $\begin{array}{l}\text { Outdoor exposure } 3 \\
\text { months from May } \\
2010^{* *}\end{array}$ & 22,700 & $118.8 \%$ & 94,550 & $67.1 \%$ & 360,500 & $106.7 \%$ & 15.9 & 15.4 & 516 \\
\hline XWOM-ST $300 \mathrm{~h}^{* *}$ & 18,700 & $97.9 \%$ & 45,350 & $32.2 \%$ & 129,500 & $38.3 \%$ & 6.9 & 15.6 & 552 \\
\hline XWOM-HT $150 \mathrm{~h}$ & 30,600 & $160.2 \%$ & 93,000 & $66.0 \%$ & 412,000 & $121.9 \%$ & 13.5 & 15.7 & 5 \\
\hline SXWM-ST 204 h & 21,350 & $111.8 \%$ & 54,050 & $38.3 \%$ & 183,500 & $54.3 \%$ & 8.6 & 14.9 & 547 \\
\hline SXWM-HT 60 h & 17,950 & $94.0 \%$ & 58,000 & $41.1 \%$ & 226,500 & $67.0 \%$ & 12.6 & 16.6 & 555 \\
\hline MWM-ST 72 h & 17,300 & $90.6 \%$ & 46,850 & $33.2 \%$ & 117,200 & $34.7 \%$ & 6.8 & 16.8 & 562 \\
\hline MWM-HT 48 h & 11,350 & $59.4 \%$ & 35,350 & $25.1 \%$ & 70,950 & $21.0 \%$ & 6.3 & 17.1 & 632 \\
\hline FUV-ST $120 \mathrm{~h}^{* *}$ & 32,000 & $167.5 \%$ & 86,000 & $61.0 \%$ & 361,000 & $106.8 \%$ & 11.3 & 17.0 & 570 \\
\hline FUV-HE 96 h** & 27,050 & $141.6 \%$ & 73,900 & $52.4 \%$ & 320,500 & $94.8 \%$ & 11.8 & 17.1 & 558 \\
\hline FUV-HT $48 \mathrm{~h}^{* *}$ & 31,100 & $162.8 \%$ & 100,650 & $71.4 \%$ & 401,000 & $118.6 \%$ & 12.9 & 15.2 & 496 \\
\hline FUV-HTHE $32 \mathrm{~h} * *$ & 30,100 & $157.6 \%$ & 93,350 & $66.2 \%$ & 369,500 & $109.3 \%$ & 12.3 & 16.0 & 550 \\
\hline
\end{tabular}

*Average between the irradiated and reverse sides of the test pieces; ** From [16].

sample, and the fraction of high-molecular-weight molecules (order of $10^{6}$ to $10^{7}$ ) of the outdoor-exposed sample increased relatively compared to the non-exposed sample (dot-circle in Fig. 7). On the other hand, the fraction of high-molecular-weight molecules (order of $10^{6}$ to $10^{7}$ ) of the sample after XWOM-ST decreased in comparison with that of the non-exposed sample dot-circle in Fig. 7). The fraction of high-molecular-weight molecules of sample after XWOM-HT increased, and the molecular weight distributions of the sample after XWOM-HT exhibited an extreme approximation curve to the molecular weight distributions of the outdoor-exposed sample. High-temperature accelerated radical recombination; therefore, the amount of high-molecular-weight molecules increased and the molecular weight distributions of the sample after XWOM-HT simulated that of the outdoor-exposed sample well. The hypothesis in the authors' previous study using FUV is also supported by these results.

In Table 3, the sample after SXWM-HT showed higher $\mathrm{Mw}$ and $\mathrm{Mp}$ and lower $\mathrm{Mn}$ than that after SXWM-ST. In the authors' previous study using FUV [16], the sample after FUV-HT (BPT $80{ }^{\circ} \mathrm{C}$ ) exhibited higher $\mathrm{Mw}$ and $\mathrm{Mp}$ and lower $\mathrm{Mn}$ than that after FUV-ST. This behavior was the same as samples photo degraded after SXWM-ST and SXWM-HT in this current study (Fig. 8). It is considered that in addition to radical recombination, chain-scission also reacts; thus, increases the number of low-molecular-weight molecules. The Mn was strongly affected by the number of low-molecular-weight molecules compared to $\mathrm{Mp}$ or Mw; therefore, the sample after SXWM-HT showed lower Mn than that after SXWM-ST.

The sample after MWM-HT showed lower molecular weights (Mn, Mp, Mw) than that after MWM-ST (Fig. 9). These results are in conflict with those from other accelerated weathering instruments. Generally, in degradation reactions of PE, "auto-oxidation" occurs over long time $(\geq 100 \mathrm{~h})$ and high temperature $\left(\geq 100{ }^{\circ} \mathrm{C}\right)$ heating; therefore, this result is reasonable considering that higher temperature accelerates chain-scission by "auto-oxidation". It is considered that temperature increase could accelerate both the increase in the fraction of high-molecular-weight molecules by radical recombination and the decrease in the number of low-molecular-weight molecules by chain-scission in parallel when using accelerated weathering instruments, except MWM. Since there have not been many reports on photo degradation using (MWM), the 
data on MWM are insufficient for understanding the behavior. Further experiments using MWM is necessary.

\subsubsection{Molecular Weight and Tensile Strength}

Because the molecular weight enlargement can cause the extension of the molecular chain and increase in polymer chain tangle, it is generally considered that this enlargement increases tensile strength. The relationship between $\mathrm{Mn}$ and tensile strength $\left(\sigma_{\mathrm{B}}\right)$ has been reported as Eq. (2).

$$
\sigma_{\mathrm{B}}=\mathrm{A}-(\mathrm{B} \div \mathrm{Mn}),(\mathrm{A} \text { and } \mathrm{B} \text { are constant }) \text {. (2) }
$$

Eq. (2) means that an increase in Mn first increases tensile strength then the tensile strength approaches A. The tensile strength and elongation drastically fall below a certain $\mathrm{Mn}$ value known as the molecular weight limit [19]. However the relationship between the molecular weight distribution and tensile strength remains unexplained. The width of the distribution varies according to the polymerization conditions, but the width does not affect the tensile strength of the polymer. It was considered that the reduction in tensile strength by photo degradation derived from the decrease in molecular weight and stress concentration [19]. In this and other studies [5, 10, 16], Mn and/or Mw of photo degraded PE increased compared to that of non-exposed samples in some cases. In addition, some studies [9, 15] reported that high-molecular-weight molecules in molecular weight distribution curves of photo degraded PE increased compared to that of non-exposed samples in some cases. In these cases, it is considered that temperature increase accelerates both radical recombination and chain-scission in parallel.

For analyzing the relationship between molecular weight and physical properties, the authors conducted single regression and multiple regression analyses using the data described in previous studies [10, 11]. The authors used molecular weights as explanatory variables and physical properties as target variables. The physical properties of high-polymer material also depend on crystallinity; however, for simple analysis, the authors did not consider crystallinity for this study.
The previous studies $[10,11]$ contain the data of $\mathrm{Mn}, \mathrm{Mw}$, and elongation. From the data of Angulo-Sanchez et al. [10], Mn had the highest correlation coefficient with elongation in single regression analysis $(R=0.89)$. At the same time, the correlation coefficient adjusted for the degrees of freedom in multiple regression analysis using both $\mathrm{Mn}$ and $\mathrm{Mw}$ did not increase from single regression analysis using $\mathrm{Mn}$ only as an explanatory variable. From the data of Berlang-Duarte et al. [11] (except commercial film), $\mathrm{Mw}$ had the highest correlation coefficient with elongation in single regression analysis $(\mathrm{R}=0.73)$. At the same time, the correlation coefficient from multiple regression analysis using both $\mathrm{Mn}$ and $\mathrm{Mw}$ did not increase from single regression analysis using $\mathrm{Mw}$ only as an explanatory variable. From these results, the relationships among $\mathrm{Mn}, \mathrm{Mw}$, and elongation of molecular-enlarged PE by photo degradation varied from occasion to occasion, and the correlation coefficient from multiple regression analysis did not increase from single regression analysis.

Therefore, the authors conducted single and multiple regression analyses using the data including newly introduced Mp. The data in Table 3 were used for these analyses. In Fig. 3, at a range of 50-100\% elongation retention, the relationship between tensile strength and elongation was directly proportional. Further, in Figs. 1 and 2, the relative standard deviation of tensile strength was lower than that of elongation. Therefore, tensile strength was selected as the target variable. $\mathrm{Mn}$ (retention percent) and $\mathrm{Mw}$ (retention percent) were used as explanatory variables. From the results of single regression, the correlation coefficients of $\mathrm{Mn}$ and $\mathrm{Mw}$ with tensile strength were -0.263 and 0.006 , respectively. At the same time, Eq. (3) and correlation coefficient were obtained by multiple regression.

Tensile strength $(\mathrm{MPa})=-0.059 \times \mathrm{Mn}$ (retention percent $)+0.052 \times \mathrm{Mw}$ (retention percent $)+19.6$

Adjusted R (correlation coefficient adjusted for the 


$$
\text { degrees of freedom) }=0.45
$$

All correlation coefficients were lower than the results using the data from previous studies [10, 11]. For making photo degraded samples, they used only one test condition using one accelerated weathering instrument, whereas the authors used various test conditions using three instruments and outdoor exposure. For example, the sample after MWM-ST showed a decrease in both $\mathrm{Mn}$ and $\mathrm{Mw}$ from the non-exposed sample but the sample after FUV-HT increased in both $\mathrm{Mn}$ and $\mathrm{Mw}$ from the non-exposed sample. As is clear from this example, the explanation of tensile strength decrease using $\mathrm{Mn}$ and $\mathrm{Mw}$ as explanatory variables is difficult. From the authors results and previous results [16], the behaviors of $\mathrm{Mp}$ in the process of photo degradation were different from those of Mn and Mw. There was no instance of $\mathrm{Mp}$ increase by photo degradation, and all degraded samples exhibited lower Mp than the non-exposed sample. Therefore, the authors conducted single regression and multiple regression analyses using $\mathrm{Mp}$ as well as $\mathrm{Mn}$ and $\mathrm{Mw}$ as explanatory variables. From the results of single regression, the correlation coefficients of $\mathrm{Mn}, \mathrm{Mp}$, and $\mathrm{Mw}$ with tensile strength were $-0.263,0.528$, and 0.006 , respectively. At the same time, Eq. (4) and correlation coefficient were obtained by multiple regression.

Tensile strength $(\mathrm{MPa})=0.130 \times \mathrm{Mp}$ (retention percent $)$

$$
-0.063 \times \mathrm{Mw} \text { (retention percent) }+14.6
$$

$$
\text { Adjusted } \mathrm{R}=0.80
$$

Both $\mathrm{Mn}$ and $\mathrm{Mw}$ of some of the degraded samples increased compared with those of the non-exposed sample, but $\mathrm{Mp}$ in such samples certainly decreased. On the other hand, in the multiple regression formula, a partial regression coefficient of $\mathrm{Mw}$ was negative.

It is generally known that a polymer of high molecular weight has high tensile strength and high resistance to a decrease in such strength. Accordingly, the negative partial regression coefficient of $\mathrm{Mw}$ is not consistent with common belief. Therefore, the authors discuss the following hypothesis of degradation behavior that includes molecular enlargement.

(1) The molecular chains could bind together by radical recombination;

(2) Elongation decreases by freedom-degree reduction of molecular chain;

(3) The stress which originally dispersed to some chains concentrated on fewer chains. Consequently, tensile strength decreases.

The correlation coefficient hardly improved even if it introduced $\mathrm{Mn}$ into the multiple regression, and correlation R decreased slightly; therefore, Mn was not used as an explanatory variable. Because low-molecular-weight molecules, which largely contribute to $\mathrm{Mn}$, do not occupy a large volume, it is considered that Mn has a low correlation with tensile strength. In this paper, both $\mathrm{Mn}$ and $\mathrm{Mw}$ of some of the degraded samples increased compared to those of the non-exposed sample, but $\mathrm{Mp}$ in such samples decreased. The authors concluded that the multiple regression formula. using $\mathrm{Mp}$ and $\mathrm{Mw}$ as explanatory variables may provide a simple explanation well for the decrease in polymer tensile strength.

\section{Conclusions}

The new test condition using XWOM at higher temperature increased the number of high-molecular-weight molecules and greatly increased the acceleration ratio of degradation (1.64 times) compared to that of the standard XWOM test at the point of tensile strength, and the molecular weight distributions of the sample approximated well to that of the outdoor-exposed sample. Because PE is the most basic high-polymer material, this new test condition might be more suitable than current test condition for other polymer materials.

The relationship between tensile strength and elongation was expressed in one line regardless of the type of accelerated weathering instrument or test condition.

From comparison of IR spectra of samples photo degraded at approximately the same tensile strength 
degree, samples degraded at lower temperature exhibited larger carbonyl $\mathrm{C}=\mathrm{O}$ stretching absorption $\left(1,715 \mathrm{~cm}^{-1}\right)$ and larger $\mathrm{C}-\mathrm{O}$ stretching absorption except for ester $\left(1,000-1,200 \mathrm{~cm}^{-1}\right)$ than samples degraded at higher temperature. Samples degraded at higher temperature exhibited larger ester $\mathrm{C}=\mathrm{O}$ stretching absorption $\left(1,740 \mathrm{~cm}^{-1}\right)$ than those degraded at lower temperature.

The multiple regression formula using newly introduced $\mathrm{Mp}$ and $\mathrm{Mw}$ as explanatory variables could provide a simple explanation for the decrease in polymer tensile strength.

\section{Acknowledgments}

The authors acknowledge the support and contributions of Mr. Ryuichi Nishio of NTT-AT, Mr. Kiyoshi Ichikawa of NTT-AT IPS, and Mr. Takuya Kamisho of NTT-EAST.

\section{References}

[1] Reich, L., and Stivala, S. S. 1969. Autoxidation of Hydrocarbons and Polyolefins. New York: Marcel Dekker. 1-127 and 456-75.

[2] Holmstrom, A., and Sorvik, E. M. 1978. "Thermooxidative Degradation of Polyethylene. I and II." J. Polym. Sci. Polym. Chem. 16: 2555-86.

[3] Norrish, R. G. W., and Bamford, C. H. 1936. "Photodecomposition of Aldehydes and Ketones." Nature 138: 1016

[4] Norrish, R. G. W., and Bamford, C. H. 1937. "Photodecomposition of Aldehydes and Ketones." Nature 140: 195-6.

[5] Rabek, J. F. 1995. Polymer Photo Degradation: Mechanisms and Experimental Methods. London: Chapman and Hall. 22-3, 24-30, 67-199, and 503-32.

[6] Al-Malaika, S. 2004. "Perspectives in Stabilisation of Polyolefins." In Long-Term Properties of Polyolefins; Advances in Polymer Science 169, edited by Albertsson, A. C., Berlin: Springer.

[7] Hakkarainen, M., and Albertsson, A. C. 2004. "Environmental Degradation of Polyethylene." In Long-Term Properties of Polyolefins; Advances in
Polymer Science 169, edited by Albertsson, A. C., Berlin: Springer.

[8] Guillet, J. E. 1980. "Studies of The Mechanism of Polyolefin Photo Degradation." Pure \& Appl. Chem. 52: 285-94.

[9] David, C., Trojan, M., and Daro, A. 1992. "Photo Degradation of Polyethylene: Comparison of Various Photo Initiatorsin Natural Weathering Conditions." Polym. Deg. Stab. 37: 233-45.

[10] Angulo-Sanchez, J. L., Ortega-Ortiz, H., and Sanches-Valdes, S. 1994. "Photo Degradation of Polyethylene Films Formulated with a Titanium-Based Photosensitizer and Itanium Dioxide Pigment." J. Appl. Polym. Sc. 53: 847-56.

[11] Berlanga-Duarte, M. L., Angulo-Sanchez, J. L., and Gonzalez-Cantu, M. C. 1996. "Study of Polyethylene Photo Degradation in Formulations with a System of Interacting Photostabilizersand Antioxidants." J. Appl. Polym. Sci 60: 413-24.

[12] Costa, L., Luda, M. P., and Trossarelli, L. 1997. "Ultra High Molecular Weight Polyethylene-II. Thermal- and Photo-Oxidation.” Polym. Deg. Stab. 58: 41-54.

[13] Tidjani, A. 2000. "Comparison of Formation of Oxidation Products during Photo-oxidation of Linear Low Density Polyethylene under Different Natural and Accelerated Weathering Conditions." Polym. Deg. Stab. 68: 465-9.

[14] Lacoste, J., and Carlsson, D. J. 1992. "Gamma-, Photo-, and Thermally-Initiated Oxidation of Linear Low Density Polyethylene: A Quantitative Comparison of Oxidation Products." J. Polym. Sci. A Polym. Chem. 30: 493-500.

[15] Tanaka, A., Miyagawa, E., Uno, H., Kitamura, M., and Nitta, K. 2000. "Influence of Morphology on Photo-Degradation of Low Density Polyethylene Films." Polym. Eng. Sci. 40 (9): 2007-13.

[16] Miwa, T., Takeshita, Y., Akage, Y., Watanabe, M., Takaya, M., and Sawada, T. 2015. "Comparison of the Photo Degradation Behavior of LDPE Using Accelerated Weathering Instruments." Corrosion Engineering 64 (4): 99-106.

[17] Costa, L., Luda, M. P., and Trossarelli, L. 1997. "Ultra-high Molecular Weight Polyethylene: I. Mechano-Oxidative Degradation.” Polym. Deg. Stab. 55: 329-38.

[18] Nielsen, L. E. 1962. "In Mechanical Properties of Polymers." Chapman and Hall 115-118.

[19] Honma, S. 2003. Japan Plastics, 54 (11): 95-102. 